
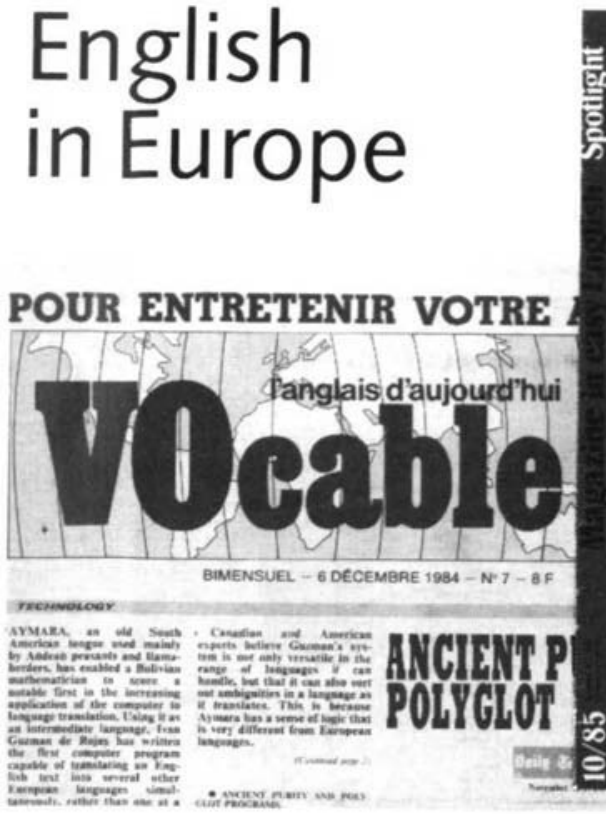

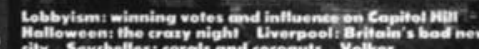

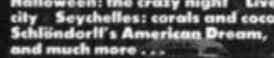

\title{
How to kill a writer
}

The National Council of Teachers of English (or NCTE) in the United States has taken up cudgels against the practice of getting students to engage in writing as a punishment. John C Maxwell, the NCTE executive director, puts the case against such punishments in an article in Education Week (28 Aug 85), where he says:

'Yes, there are such teachers. And what a terrible thing it is that they do. By such actions, teachers can quickly undo the hard work of teachers of English language arts who struggle to persuade young people that writing is an enjoyable human experience, a way of sharing ideas ... a way of phrasing both the expressible and the virtually inexpressible thoughts that course through all our heads.

'Writing is the last of the language arts to develop. As most of us know from spending a lifetime learning how to write, early experiences are critical to later development. If even a part of one's first experience with writing is painful, the road to competency in written language is made immeasurably harder. We are a nation that, by and large, is afraid of writing. Many of us will go to considerable lengths to avoid it.'

Maxwell agrees that writing is difficult work at the best of times, and argues that it has been made even more of a problem with the passing of corporal punishment: 'It is possible that writing as punishment has taken the place of the principal's paddle... But making them write mindlessly and painfully only invites the kind of distaste for writing that shows up in the behavior of too many adults. It is about time we policed ourselves by driving this insane practice out of the schools. Too much is at stake. If we ever expect to become a nation of writers, we must stamp out writing as punishment as soon as possible.'
In ET4 we showed pictures of the covers of two Italian publications devoted entirely to helping people improve their command of the English language; they were The Reporter and Speak Up. Here we display two more: Anglo-American Spotlight: Das deutsche Magazin in englischer Sprache from West Germany, a monthly published by Spotlight Verlag, Postf. 1267, 8036 Herrsching am Ammersee; and VOcable, L'anglais d'aujourd' hui from France, a bimonthly published from Rue de la Vanne, 92120 Montrouge. If readers know about other publishing ventures like these, we would be glad to hear about them.

\section{The BCAnglos}

In the EFL Gazette (London, Sept 85), Barry Tomalin of the BBC reports on a gathering in Montevideo, capital of Uruguay, where in July, 300 teachers and teacher trainers for seven Latin American countries recognised, perhaps for the first time, what a powerful network they represent.'

They were participants in the first International Conference of Latin American Cultural Institutes, popularly known from Mexico to Argentina as 'Culturas' or 'Anglos'. There are about a 100 of them all told, each with a number of affiliated schools, employing about 1,000 teachers, and providing courses in any one term to approximately 200,000 students.

The Latin-American Anglos are nonprofit-making organizations that teach English to all ages and at all levels. They were set in motion half a century ago by the British Council, 'as part of its aim of disseminating British culture abroad'. Things did not develop quite as planned, however, in that culture quite rapidly took a back seat to language. Today, links with the British Council vary from institure to institute, and the teaching staff is now generally Latin American, with Latin American attitudes to the language.

\section{Linguistic sins of the fathers}

As Christopher Young observed in the Montreal Gazette of 15 June 85: 'The jealous God of the Old Testament warned the Children of Israel that he would "visit the sins of the fathers upon the children unto the third and fourth generation." It's a fearful thought, but something like that has happened to the people of Manitoba.'

The sins were blatant enough, and were linguistic. As part of the deal when the Red River Colony became a province of Canada to be known as 'Manitoba', the Manitobans of the time promised the federal government that all future provincial laws would be written down in both English and French. They broke that promise, and almost a century later (the sins began in 1890), the Supreme Court of Canada has thrown the book at Manitoba's current legislators: the province must translate almost a hundred years of legislation into French as soon as it can in order to live up to the nation's constitutional bilingualism and that ancient broken agreement.

The original failure was fuelled in part by Protestant distaste for Catholics, English-French tensions, and a fear among the anglophone leaders of the new province that, if the French got away with it, then all the new people flooding in from Europe would also insist on their own languages and separate religious schools. Encouraged, however, in recent years by the stance of Quebec for French and against English, the Franco-Manitoban minority has pressed for its rights - and got them. The result should be a lot of work for translators from Quebec. 